\title{
A Search for Genuine Regionalism: A Regenerative Agenda for the Peripheries
}

\author{
Vilmos Katona
}

\begin{abstract}
Considered to be the answer to the problem of globalisation, the "architecture of resistance" was exposited by Frampton (The anti-aesthetic: essays on postmodern culture. Bay Press, Port Townsend, pp. 16-30, 1983) in his polemical essay of the Six points, and illustrated through practice by some architects. The power and degree of the architectural 'resistance', though, was restrained by its rather aesthetic focus. As Moore (Constructing a new agenda: architectural theory 1993-2009. Princeton Architectural Press, New York, pp. 365-384, 2007) points out Frampton's modern regionalism was not based on a political perspective, but on a concept that stressed summarising the history of architecture from an individual aspect, rather than declaring a new agenda for praxis. In his non-modern manifesto Moore (Constructing a new agenda: architectural theory 1993-2009. Princeton Architectural Press, New York, pp. 365-384, 2007) claims the necessity of the production of a regenerative architecture, instead of basing academic considerations on design, will participate in the construction of integrated cultural and ecological processes by magnifying local labour and constructing the technologies of everyday life. Regeneration has an impact on solving the economic trauma in today's peripheral societies by motivating the centre to reconsider its role about natural sources of sustainability. Subsequently, we cannot reject the idea expounded by Solà-Morales (Differences: topographies of contemporary architecture. MIT Press, Cambridge, pp. 57-72, 1987), of the possibility of a new life springing from half-abandoned or marginal areas. What is the unique architectural self-reference that is still untouched by reproducible technologies and global political interventions? To respond to this question, this chapter takes a closer look at the latest relevant tendencies of the architecture of the 'Marginal Worlds'.
\end{abstract}

Keywords Critical regionalism - Genuine regionalism - Regenerative architecture $\cdot$ Terrain vague $\cdot$ Architectural identity $\cdot$ Local technology

\footnotetext{
V. Katona $(\bowtie)$

Faculty of Architecture, Budapest University of Technology and Economics,

Budapest, Hungary

e-mail: Katwilat@gmail.com
} 


\section{Introduction}

For many years, we have shared the common desire to understand architecture as something capable of reuniting place and technology, and tradition and innovation. Warned by the adverse effects of the globalised world, we have spent decades contemplating the problems arising from the loss of architectural memory, and lamenting any effective countervailing forces. During the relatively balanced years when critical regionalism first appeared, the emphasis of the theory was on how to save our heritage without restricting the power of the avant-garde. Both the traditional ways of building and the innovative impetus were in danger; however, our resources seemed to be abundant. All the academic discussions about a return to an industrialised society depicted a rather romantic dreamscape, which was illusory, but forgivable during an epoch of economic upheaval. Today we realise that the Earth's resources are not inexhaustible; natural and manmade disasters are monumental in their magnitude, and the values that propelled the Industrial Revolution are today held in wide disrepute. The latest world economic crisis has found us unprepared. The first reason for this lack of being prepared is the long-term isolation of the West from the Eastern countries.

When Harris (1958) spoke about the oppositions between centres and margins, he noted the liberal context of California initiatives within the more strict national regulations of the United States, and may not have foreseen that his 'microcosmic' intention could be a model applied on a wider scale at a later time. After the fall of the Iron Curtain, in a politically and ideologically divided Europe in 1990, the Eastern Bloc suddenly joined the Western economic system and embraced it wholeheartedly. From an Eastern point of view, the capitalisation of these European countries made them the national peripheries of the liberating, global West. What liberalism meant to Harris (1958) in North America is now taken as national conservatism in Eastern Europe. The West appeared as the political centre, as well as a united market for free trade. Impoverished countries celebrated their freedom offered by the regime change, but soon recognised their new financial dependence. Confusion grew with the Western world opening its gates, resulting in a disorientation of politics. The new margins of the globalised world could not decide whether they should resist assimilation or accept it, mostly because of the communication twist that has inverted the meanings of liberalism and nationalism (Vais 2008). It remains pertinent today whether the global model represents a centralised or multi-centred one, or hierarchical or cooperative relation between the associated countries (Čeferin 2008: 54). There did not seem to be enough time to bridge divergent points of view, and to arrive at solutions through mutual participation.

With China and the Eastern developing states opting for the world economic 'interface' at an accelerated speed, globalism had spread over most of the Northern Hemisphere; but several Southern countries of the Third World have chosen to follow a growing process as well, which was formerly called 'western type'. After North America's question on the unity of its states and the dissolution of Europe's political schism, we are focusing on the third level of the centre/margin paradigm, 
which is the north-south relation. Geometrically, it is the final and the largest shift. What mostly distinguishes the two hemispheres is that the political, demographical and economic stability of the North is relatively higher, while the South has embraced less a 'common will'. Thus, it appears to be globally more chaotic but locally more fundamental. These parts of the world know how to survive better in moments of disaster and poverty. They do not know the meaning of consumerism for they cannot afford wastage. Apparently, they would be less sensitive to a future cataclysm than the North with its shield of unity broken. It is time to learn from them.

It would be a mistake, though, to consider the North as perfectly globalised, for there are still parts that are uninfluenced. The spirit of traditions, for example, is avoided by the global policy which leaves every value out of consideration that qualitatively eclipses the level of materiality. It is mostly the consequence of the rapidity of the period for which it has no time to attain full growth. These policies only affect what can be grasped easily: the quantitative and the statistical (Guénon 1945). For this reason, we turn to the quantitatively modest but qualitatively advanced to find examples for regeneration.

\section{Features of Local Regeneration: Non-modern and Non-aesthetic}

International modernism could have been considered as an attempt to develop an architectural language to exchange local experiences, but it has rather acted as a policy for the neutralisation of identities. In the history of modern architecture, we find its roots in the work of CIAM, especially in its pre-war congresses. Looking back in time, we can re-evaluate this period on the one hand as a sincere wish to spread social equality by solving the lack of habitable residences throughout the world, but on the contrary as a dramatic tendency that theoretically uniformised human beings. The Athens Charter, along with Le Corbusier's aggressive rhetoric for a mechanised architecture (Jeanneret 1923, 1957), clearly suggests that the city should functionally satisfy the minimal needs of people and that the products of the dynamically evolving technology should likewise appeal to their tastes. The Charter describes well how every city should look, based on the physical parameters of an average person. This implies the negligibility of both the contextual differences between the places where the cities are planted and the personal differences between the cultural identities, lifestyles, abilities or the temperament of the people who live there. The CIAM connected international modernism to uniformity.

This is the main reason why we encourage a non-modern approach to regionalism. It is time to focus on the real, instead of the statistical, human being that is Aristotle's zoon politikon. 'Politikon' refers to the self-consciousness, the teleological character of a man, and the organised state or society as the background for human life. The Greek phrase also implies humanity's freedom to designate and 
arrange its place for living. Without this freedom, there is nothing that differentiates human beings from the rest of the animal kingdom. Therefore, the ability to create a place for dwelling in a society is an essential premise, which makes us uniquely human. Human beings build, not only for themselves as individuals but, for many in society. This relates closely to Heidegger's (1951) ontological explanation on the unity of building, dwelling and thinking.

Humanity distinguishes itself by creating, and not by merely choosing aesthetically from pieces that are already given. As Frascari (1984: 500) explains, constructing (logos of techné) is in a 'chiastic' relation with construing (techné of logos). By putting structural pieces of the building together, the architect construes their design. No plan can be implemented without the feedback of its construction, the materials, and the place, which always compromise the general concept. Without this interference, architecture becomes a self-referential play, leading to dissimulation. The 'chiastic' relation also sheds light on the secret of creation. The process cannot be fully controlled by man. Thus, the experience of the construction by doing reveals how ephemeral human efforts are. Still, the building astonishes the architect by being plausible at the end. Only local labour can recognise the immanence that connects human effort to a higher intelligibility. This is why local workforces are so essential to understanding regeneration. The source of the power which builds up the house is somewhere between matter and plan. To understand this, the architect needs to work together with the labourers: the masons, the joiners, the carpenters and so on. These labourers need to feel the resistance of materials as well as the lightness of a perfect joint. From element to element, all pieces have their role in the whole, as all the labourers contribute to the working community. During the months of a well-organised construction, the collective consciousness of the labourers evolves to work more efficiently and to be more sparing of resources. Their community turns into a local identity that is the origin of the story of the building. This is one way how architecture regenerates work power and identity without any aesthetic argumentations before the work of art.

The other reason why a regenerative architecture should take aesthetics as secondary is included in Moore's manifesto. Moore (2007: 377-378) argues the primordial premise for regional thinking is not the academic dispute as to what the building should look like, but the political will which encourages people to use their natural skills and local resources freely. Because of the bureaucracy which makes it illegal to work out direct solutions without first going through the red tape of seeking permissions, architects refuse to coordinate the construction on site. Decisions are divided between a central office for construction law and the actual planning team, which is taken as the legal periphery of the former. It is no wonder that the natural beauty of the local building is also understood as secondary to former aesthetic priorities. As a result of centralisation, today's interest in aesthetics substitute or mask politics in architecture. Both the modern uniformisation and the aesthetic prioritisation object to the direct experience of architecture, which is the key to regenerating local identities. Therefore, a genuine regionalism is nonmodern and non-aesthetic. 


\section{Essential and Real}

The subject of phenomenology is the essence of objects, either conceptual or real. Motivated by the wish to understand the entia rationis ${ }^{1}$ of the building, the only phenomenology can approach architecture close enough to touch its essence. This is traditionally done by contemplation, which prepares the intellect to catch the central meaning intuitively. What intuition finds is not a definition referring to other objects or final axioms, but the a priori truth revealing itself in the most immediate way. Instead of encouraging random associations, phenomenology guides us in seeking the a priori core of architecture that is certain, inevitable and the most intelligible.

As illuminated by Hildebrand (1976: 63-138), the absolute confidence of a priori knowledge is not something transcendental and unreachable for mortals. On the contrary, its intelligibility makes it available to everyone. The truth revealed by contemplating the essence of architecture is explicit in simple judgements like good/bad, harmonic/disharmonic, useful/useless, original/reproduced, and so forth. It also appears in simple statements about the structures, the textures or other characteristic elements of the building. None of these declarations will be self-referential or tautological, to the a priori truth does not lie in the repetition of basic attributes but the recognition of an essential nexus between two independent objects. The phenomenological truth is always synthetic as a joint.

Many of these syntheses can be found in symbolic statements about the building. If, for example, when looking at a rafter of a wooden roof, we state that "the softest contacts between structural elements are as perfect as a geometrical cut" (Frampton 1990: 522), after which we recognise that "any geometrical cuts are too perfect to be tangible" than an a priori truth is revealed to us about materiality: namely, that imperfection and tangibility are premises of material reality. If it is so simple, why is it a priori? It is because our statement was made after remembering the essence of geometry and matter without making any conclusions, or evocations of prior experiences. The most important fact is that the statement was initiated by contemplation about a particular architectural structure available for everyone, without which the truth about it may not have been revealed. This well illustrates that essential truth is not necessarily transcendental, but lies in the physical reality as well. We do not have to design monumental Platonic solids for allegorising truth, for it is enough to start building a shed in a contemplative spirit.

The closer we get to the subject of architecture, the deeper contemplation is needed. As we have just seen, this is not done by theory but by making in the real world. Consequently, the search for the essence of architecture is the most practical approach of which we can speak. As contemplation is done on site, the local building is an adequate way to start an intimate relation with architecture's phenomenological subject. The subject and the essence of architecture are revealed by the reality of an intimate local labour. The local building is the core unit of regional

\footnotetext{
${ }^{1}$ Entia rationis, in metaphysical world, is only rational and exist in mental world and thought to exist in mind only but doesn't exist in real (Bunnin and Yu 2004: 211).
} 
architecture, which only differs from the former in scale. Genuine regionalism depends upon local labour with the stamina to reveal the essence of architecture, which is present in the practical reality of building. Genuine regionalism is both essential and real.

\section{Adaptive and Resistant}

Genuine regionalism does not mean a new protocol for architecture. The six points for the 'architecture of resistance' presented by Frampton (1983) are secondary to the political background. This makes them implementable by encouraging local labour, the use of local resources, and regional planning. Frampton's affection for the tectonic is not based on a phenomenological certainty, but on the viewpoint of a carpenter. The will to find an architectural attitude that is capable of resisting the confrontations with the interest in globalisation allows a much more colourful palette of solutions than the tectonic. As it was explained by Katona (2010), even the actual meaning of tekton implies the freedom to fabricate textures not necessarily following the logic of the load-bearing structure. It is evident that primitive cultures which carve their homes out of porous cliffs, or others who erect thick whitewashed walls against the heat, do not build according to the tectonic, but rather to the stereotomic system. This fact does not discourage them from forming local communities and building in their traditional way. Of course, if they ran out of clay, some of them would search for another place to live or call other people to teach them how to build differently. A genuine regionalism adapts to the changing local conditions.

Regions look back on their history of technological evolution according to the altering needs and circumstances of the place. Adaption to the local facilities, though, does not mean a compromise against uniformised technology, which restricts the rich possibilities of regeneration by expelling the one offered by the place. It is cardinal, therefore, to make a strict distinction between uniform and sui generis (defines as 'of its own kind') technologies. Regionalism cannot and does not need to resist technology, but it can counteract uniformisation with its technological development as exemplified in the case of some contemporary manufacturers.

Moore disapproves critical regionalism because of its being too permissive towards modern academism. Moore's regionalist exhortation still suffers from a compromise between the irreproducible and the uniform, as is readily demonstrated in his cross diagram (Moore 2007: 374). Place and technology determine the two perpendicular axes in Moore's diagram (Fig. 1) and divide the plane into one field with double positive coordinates, another with double negative coordinates, and two other fields with mixed coordinates similarly to coordinate geometry.

The system was prepared by placing all the aspirations of contemporary architecture into one diagram. From the diagram, it can be seen that Moore determines place and technology as separate, independent criteria with no influence on each other. 'Orthodox' modernism is positioned in the field $(-;+)$ while postmodernism 
Fig. 1 The value opposition of place and technology in modern thought (Moore 2001: 135)

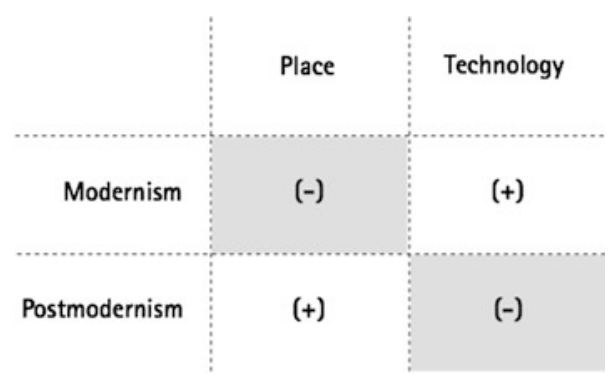

is placed in the field (+;-). Taking this simply, it means that according to Moore, modernism works against place but for technology, while postmodernism works for place but against the determination of technology. Accordingly, critical regionalism can be found in the field (+;+), and while an antagonist of it, 'radical nihilism' is placed in (-;-). From this formula, it can be clearly seen that critical regionalism is positive both regarding place and technology. These features make critical regionalism analogous with its intention to respect tradition and reform power at the same time. Nevertheless, there is a problem with this concept, for an anomaly reveals the most obvious contradiction of this double will.

Is technology significant enough in itself to be considered as a factor independent of place? If we could find a technology independent from the place, it can be none but a universal technology, which is the same under any conditions. However, can we talk about any universal building technologies reproduced independently from local resources, needs and tradition? We can do so only regarding the general outcome of the construction industry - the result of modernism's international achievements from a historical point of view - and recently of the market of uniform industrial products (Katona 2012: 150-153). The diagram's 'technology' represents globalism as a consequence.

Moore fails to distinguish sui generis from uniform technology. This omission exposes critical regionalism because it shows that critical regionalism makes a compromise between the local and the globalised. Therefore, we need to reinvest critical regionalism with the 'architecture of resistance'. This can be achieved by genuine regionalism which adapts to the alterations of local conditions, but is resistant to the uniform. Genuine regionalism does not provide architecture with design protocols but is founded on sui generis technology.

\section{Genuine Regionalism}

The following examples will demonstrate some of the features of genuine regionalism. These examples were not found because of an aesthetic preconception about what architecture and regional design should be, but have been chosen because they derive from an irresistible call for a phenomenon that has lost our attention. That is 
to say; the examples antedated the recognition of the tendency behind them. We emphasise that the listed examples be only a few of the many unknown. Our global communication facilities made it possible to access them through the works of prestigious designers, some due to being mentioned here, but their effort, in fact, targets the nameless.

\section{Need and Limits}

In his essay about weak architecture, Solà-Morales (1987) illustrates that there is always a chance for rebuilding even if there are no examples of how it should be done. What Solà-Morales speaks about is the hidden reserve of vacuity that is present in wastelands, drosscapes (Berger 2006), or fields hit by disasters. Until these territories are reutilized (erased/replanted) for the global economic interest, they appear infertile, marginal and in-between. What is of interest here is how they are excluded from space, and fall out of time. Still, they do not disappear by being prescribed by these domains. On the contrary, we can experience them in a more meaningful way. Compared to wastelands or drosscapes, the life of operating cities appears to be partial, and finite. One could spend days in a deserted factory yard or an abandoned village without seeing movement or activity. Although the colours, the patterns or the contours may differ, the calmness of these places is the same everywhere. It is adequate to say that this phenomenon of wastelands is both more pervasive and virile than the delicate, even fragile, political equilibrium maintained by globalised architecture

The evaluation of aesthetics as a fixed point for regeneration in an age losing its orientations by Solà-Morales (1987) is to be doubted. Aesthetics helps to identify a community or a region, but aesthetic value depends on the restoration of the common will to build and the freedom to use local resources. Where vacuity enters into human thought, need appears and wants to be fulfilled in the most direct way. It is what makes terrain vague, immediate and pervasive. These qualities of terrain vague make it informal and serve to identify it and evoke regeneration. Accordingly, we take the vacuity of 'Marginal Worlds' (Heidegger 1969) as the primordial source of regenerative architecture.

The peripheral fields' quasi-space is avoided by global interest because it is not a potential market for the production of uniform products. A regenerative strategy, therefore, will be kept intact by globalism until it starts to sell talent, as a trademark (Čeferin 2008: 51). As soon as local technology promotes itself as 'the alternative', it exchanges its natural character for an aesthetic one. This is the way it loses its flexibility and freezes evolution, thus becoming unaccommodating to the challenges of the alternating local conditions. A local architecture of this kind soon segregates itself from the building community and becomes formal instead of being essential. By giving up its limited nature, it will lose contact with local needs.

The workshops of Martin Rauch operating in Schlins and several other villages in the Vorarlberg region of Austria are examples of this (Kapfinger 2003). Rauch 


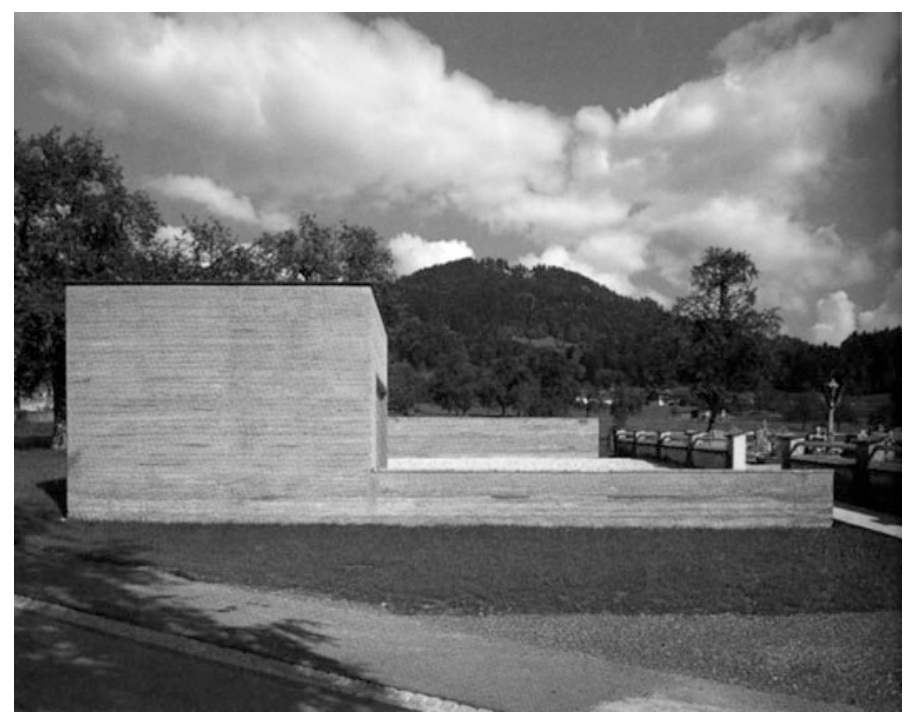

Fig. 2 Funeral Chapel in Batschuns, Austria, designed by Stefan and Bernhard Marte, 2002 (source http://szakralis.wordpress.com, re-accessed on 25 February 2016)

made the plans for the rammed earth walls of a funeral chapel in Batschuns 2002 designed by Stefan and Bernhard Marte (Fig. 2).

The project revitalised the building community by getting people to take part in the construction. Rauch taught villagers to build from local soil, getting them involved in the process of erecting walls layer by layer (Anon 2006). They used a unique moulding technology that was inspired by the local mud houses. The foundation of the chapel was a popular decision of the village using the empty land of the expanding cemetery. The site's attributes yielded the regeneration of the location towards an indigenous architecture. The exportation of the technology to the Berlin Wall Reconciliation Chapel (2002) of Rudolf Reitermann and Peter Sassenroth had not reached the same success before. Reasonable efforts were made to integrate the design into the history of Berlin soil (by mingling ruin ashes to the building mud) (Welzbacher 2001), but the construction could not exceed a symbolic level. While it became contextually narrative, the building's presence remained rather virtual.

The same thing has happened to many contemporary attempts to recover architectural authenticity. What we prefer to search for is at the margins of the globalised world. Most obviously we can find such places in the regions of famine, poverty and overpopulation. Examples appear in some parts of Africa where Hollmén Reuter Sandman Architects designed social complexes for African women and children in need. The Finnish team studied the life of local people and involved them in the building process. Their credits include the ongoing TunaHAKI Centre orphanage project in Moshi, Tanzania (HRS 2007), and the Rufisque Women's 


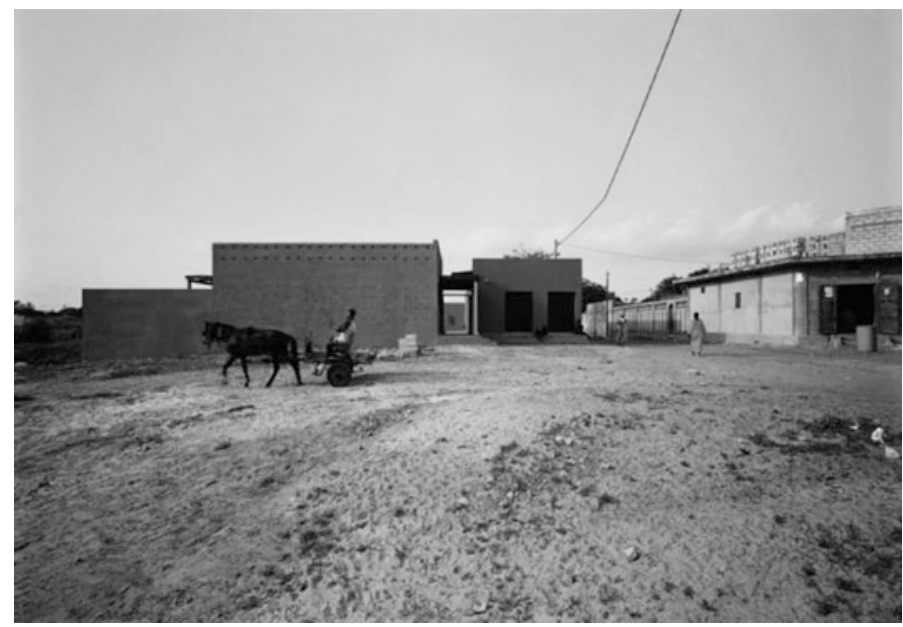

Fig. 3 Women's Centre in Rufisque, Senegal, designed by Hollmén Reuter Sandman Architects 2001 (source http://www.hollmenreutersandman.com, re-accessed on 25 February 2016)

Centre, 2001 (Fig. 3), which integrate both the local brevity and simplicity of design and the traditional village planning of the place.

By applying a fenced, square-type ground plan with an encompassed open air space in the centre, Hollmén Reuter Sandman Architects went back to the urban structure of the Ukumbis (Hollmén et al. 2005). Along with this, they posted a message to the community by opening a new village centre for the people living in the peripheries of the local society. As a sign of respect and new hope, they painted the walls of the cubic-shaped complex with a distinctive red colour, which advertises the accomplishment of the building - a fact that rarely happens in the Senegal suburbs for the inhabitants fear of high taxes. On the contrary, people here finished the construction with joy, recycling even their used glasses to make translucent patterns on the façades. The revitalisation of the Senegalese city of Rufisque's peripheries sprung from the need of the locals was built from very limited sources. The ambition that it should make the nucleus of a sustainable community emerged outside profit-oriented politics or aesthetic considerations. It does not mean, however, undermine the beauties of such urban or individual plans, for we define beauty as the expression of the essence of building (Heidegger 1935). That expression is always vital for its high potency to reveal the truth behind the work of construction.

\section{Culture and (In)dependence}

In cases of a disaster or socio-economic collapse, can vacuity enter into human space? The larger its power, the more embracing a response it generates. Regarding observations presented here, the intensity of destruction is proportional to the 
cultural depth of regeneration. As soon as a region arrives at a point of cataclysm, cultural memory is called upon in a search for solutions. This is the consequence of the lack of material values, which turns people's attention to sufficient knowledge. The stress of need generates communities, new social hierarchies, immediate action, and the recollection of knowledge that was latent. When it is a question of survival, construction becomes a collective mission to which all the members of a locally organised community will contribute according to their skills.

The's $20 \mathrm{~K}$ housing project is an example of the application of simple, but effective, architectural knowledge. It results in variations of light structure houses for residents who have a steady, low or modest income, and yet are unable to obtain adequate housing through conventional financing in the United States. These houses, which take local circumstances into account, are affordable and easy to build. The research team in the studio tests housing modules to develop small dimension urban formations as well (Mays 2007). Their projects welcomed students willing to take part in experimental programmes, who subsequently contributed to the establishment of communal buildings like clubhouses, museums and fire stations (Fig. 4). By forming independent building companies, they proved effective in overcoming the apathy and inertia that characterised central politics.

One year after Hurricane Katrina's strike in 2005, the devastated zone of New Orleans was still under water. Both federal and state governments failed to organise the recovery in time, and the insurance companies refused to compensate the victims of flooding and wind-driven water. This resulted in mass emigration, crime and disease. The opposite happened in the Central Pannonia region of Hungary where a dam collapse of the Ajka aluminium factory's settling pool poured a lake of alkaline sludge on Kolontár and the nearby Devecser in October 2010. After immediate

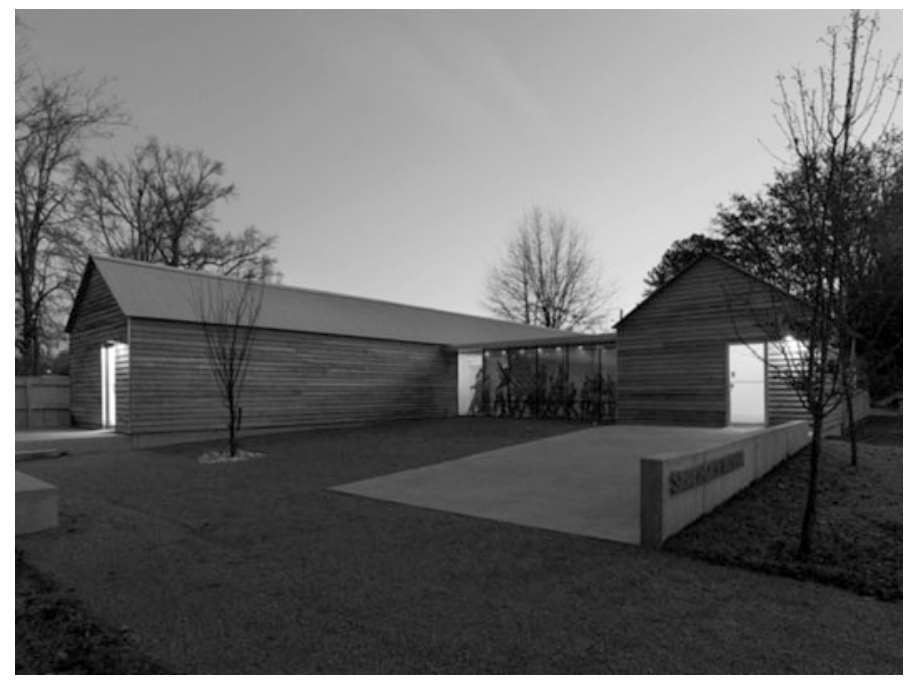

Fig. 4 Safe House Museum in Greensboro, AL, designed by The Rural Studio, 2010 (source http://www.ruralstudio.org/projects/safe-house-museum, re-accessed on 7 March 2016) 
humanitarian aid, central efforts were made to modify customary building laws to shorten reconstruction time. As a result, the new housing districts opened their gates only eight months after the catastrophe (Bechtold 2011). The building project was directly entrusted to Imre Makovecz's KKE Fellowship, whose purpose was to design more livable homes and to improve local communities. By maintaining constant communication, the team was highly successful in satisfying the communities' needs. Imre Makovecz's KKE Fellowship spent most of their time on the site together with the affected villagers, commiserating with them while giving them hope for the regeneration of their homes and communities.

Compared to the case of the $20 \mathrm{~K}$ project, the recovery in Hungary was more centrally orchestrated, and as a result, much more dependent upon central efforts. While in the case of Hurricane Katrina, central and local politics were in an adversarial relationship, the Ajka aluminium factory disaster relief work was cooperative. The cooperative relationship in the latter worked against the critical factor of regeneration, as it stimulated cultural formalism. Central politics used the excellent power of regeneration to promote and strengthen its position through architectural reminiscences of history. While the organisation of the reconstruction following the disaster eventually evolved into something that proved to be efficient and realistic, the architectural solution was superficial, for it had lost its direct relation with the essence of regeneration. The possibility of a local cultural renewal through living architectural memory was overtaken by the central political message; thus, the region quickly lost its privilege of being peripheral.

A true cultural revitalization happened in Japan after the Fukushima disaster in 2011. Among many other parallel experimental efforts (Taro et al. 2012), Kengo Kuma's office developed temporary objects of use such as paper tents that were easy to fold and unfold anywhere, but Kuma's most realistic intervention was methodological. His East Japan Project was launched to root out traditional craftsmen near the damaged zone (EJP 2011). In Sendai and other parts of the Tohoku Region, they found the last craftsmen of sewing, texturing and basketry, and encouraged them to make products for the Fukushima reconstruction. With a team of architects and designers, they started to work together and exchange traditional craft knowledge with contemporary experiences. By the same effort, they gained technical inspiration from tradition and saved a dying local culture. Since then, they have been running a workshop for scholars of both design and manufacture to maintain this practice experience. The twofold nature of mutual participation made EJP genuine and realistic, showing the interdependence and real cultural depth of regional regeneration.

\section{Conclusions and Recommendation}

Local regeneration is the origin of genuine regionalism. It focuses on the real, instead of the statistical, human being, who has the freedom to designate his place of living and build from the local cultural and material sources that the chosen place 
offers. Genuine regionalism cannot afford wastage; therefore, it turns to the quantitatively modest but qualitatively advanced. During a regenerative construction, labourers from communities to improve their consciousness in working efficiently and with sparing resources. They use architecture to reclaim work power and identity without aesthetic prioritisation predetermining the work of art. Instead of encouraging random associations about architecture, the regenerative agenda is radical in seeking the a priori core of building that is certain, inevitable and the most intelligible. It targets the subject and the essence of architecture which is revealed by the reality of an intimate local labour. Genuine regionalism has the power to adapt to the local conditions of any appropriate place, and to resist the compromise towards uniform technology. Instead, it encourages the continuation and the invention of local technologies.

Sites of terrain vague that appears after natural or socio-economic collapse provide the opportunity to identify and evoke regeneration. Accordingly, we understand the vacuity of 'Marginal Worlds' as the primordial source by which we can access the vital expression of the essence of building (i.e. beauty). The cultural depth of regeneration is determined by the degree of interdependence and the effectiveness of local politics. In the following points we summarise the general features of genuine regionalism as a recommendation for the peripheries having the unique chance to show alternatives to the globalised world by natural recovery:

- Genuine regionalism is nonmodern and non-aesthetic. Both the modern uniformisation and the aesthetic classification of objects is secondary to the direct experience of architecture, which is the key to regenerating local identities.

- Genuine regionalism is both essential and real. Genuine regionalism depends upon local labour with the stamina to reveal the essence of architecture, present in the practical reality of building.

- Genuine regionalism adapts to the changes in local conditions but is resistant against uniformity. It does not provide architecture with design protocols but is founded on sui generis technology.

Acknowledgements The author would like to thank Zorán Vukoszávlyev, Ph.D. for giving enthusiastic support during the years of the research. Thanks to Prof. Ferenc Vámossy, Ph.D. for guiding some of the relevant publications, and finally, to Sir James Reese for contributing to this work.

\section{References}

Anon. (2006). Cemetery extension and chapel of rest, Batschuns, Austria. Architecture and Urbanism, 435, 54-61.

Bechtold, Á. (2011). After the red sludge flood. Régi-Új Magyar Épitömüvészet, 11(4), 35-38.

Berger, A. (2006). Drosscape. In W. Charles (Ed.), The landscape urbanism reader (pp. 197-217).

New York: Princeton Architectural Press.

Bunnin, N., \& Yu, J. (2004). The Blackwell dictionary of western philosophy (p. 211). Wiley. 
Čeferin, P. (2008). Far from home: Contemporary Slovenian architecture in the making. In P. Herrle \& E. Wegerhoff (Eds.), Architecture and identity (pp. 47-56). Berlin: LIT Verlag. EJP. (2011). We purpose "the new lifestyle". Accessed on April 20, 2012 at http://e-j-p.org

Frampton, K. (1983). Towards a critical regionalism: Six points for an architecture of resistance. In H. Foster (Ed.), The anti-aesthetic: Essays on postmodern culture (pp. 16-30). Port Townsend: Bay Press.

Frampton, K. (1990). Rappel à l'ordre, the case for the tectonic. In K. Nesbitt (Ed.), (1996). Theorizing a new agenda for architecture: An anthology of architectural theory 1965-1995 (pp. 518-528). New York: Princeton Architectural Press.

Frascari, M. (1984). The tell-the-tale detail. In K. Nesbitt (Ed.), (1996). Theorizing a new agenda for architecture: An anthology of architectural theory 1965-1995 (pp. 500-514). New York: Princeton Architectural Press.

Guénon, R. (1945). Spatial quantity and qualified space. In id, (2001). The reign of quantity and the signs of the times (pp. 31-37). Hillsdale: Sophia Perennis.

Harris, H. H. (1958). Regionalism and nationalism in architecture. In V. B. Canizaro (Ed.), (2007). Architectural regionalism: Collected writings on place, identity, modernity and tradition (pp. 56-65). New York: Princeton Architectural Press.

Heidegger, M. (1935). The origin of the work of art. In id, (1971). Poetry, language, thought (pp. 143-162). New York: Harper \& Row.

Heidegger, M. (1951). Building dwelling thinking. In D. F. Krell (Ed.), (1978). Heidegger, Martin basic writings: Philosophy - collected work (pp. 319-340). London: Routledge \& Kegan Paul.

Heidegger, M. (1969). Art and space. Man and World, 6(1), 3-8.

Hildebrand, D. (1976). Was ist Philosophie? Stuttgart-Berlin-Köln-Mainz: Verlag W. Kohlhammer.

Hollmén, S., et al. (2005). The strength of a woman. Architecture Plus, 51(10), 26-29.

HRS. (2007). The orphanage, Moshi, Tanzania. Accessed on April 20, 2012 at http://www. hollmenreutersandman.com/p3_text.php?project_id=3

Jeanneret, C.-É. (1923). Vers une Architecture. Paris: Éditions G. Crès et Cie.

Jeanneret, C.-É. (1957). La Charte d'Athènes. Paris: Éditions de Minuit.

Kapfinger, O. (2003). Living in Earth. Architecture d'aujourd'hui, 346, 102-109.

Katona, V. (2010). Reconsidering the Tectonic: On the sacred ambivalence of the tectonic in the light of Martin Heidegger and relevant theoretical studies on architecture. Periodica Polytechnica-Architecture, 41(1), 19-25.

Katona, V. (2012). Place and identity: Critical regionalism in the new millennium, national and international achievements. Épités- Épitészettudomány, 40(1-2), 141-197.

Mays, V. (2007). The new Rural Studio, founded by Mockbee and Dennis K. Ruth. Architect, 96 (13), 74-81.

Moore, S. A. (2001). Technology place and the nonmodern thesis. Journal of Architectural Education, 54(3), 130-139.

Moore, S. A. (2007). Technology, place, and nonmodern regionalism. In A. K. Sykes (Ed.), (2010). Constructing a new agenda: Architectural theory 1993-2009 (pp. 365-384). New York: Princeton Architectural Press.

Solà-Morales, I. (1987). Weak architecture. In: S. Whiting (Ed.), (1996). Differences: Topographies of contemporary architecture (pp. 57-72). Cambridge: MIT Press.

Taro, I., et al. (2012). Architects and the Great East Japan Earthquake. Japan Architect (Winter Issue), $1-31$.

Vais, D. (2008). Regionalism between center and margins: Diamonds and water. In ead. Arhi-texte (texts): în Căutarea unei noi Modernităţi (pp. 237-241). Bucharest: Arhitext Design.

Welzbacher, C. (2001). Kapelle der Versöhnung, Berlin. Deutsche Bauzeitung, 135(11), 70-75. 